\title{
Diagnosis and Nursing Care for Patients with Gastric Tumors Treated at the Outpatient Clinic of the Group for Research and Treatment of Gastric Cancer
}

\author{
Maria Teresa Santos Guedes ${ }^{1}$, Luciana Martins Valente ${ }^{2}$, Mônica Aparecida \\ Porto $^{3}$, Marysse Lanes ${ }^{4}$, Maria Amália Cury ${ }^{5}$, Maria Aparecida de Luca \\ Nascimento $^{6}$, Ann Mary Tinoco Feitosa Rosas ${ }^{7}$ \\ 1,3,4,5 Oncology nurses - Outpatient Clinic of the Cancer Hospital I, Brazilian National Cancer Institute. \\ ${ }^{2}$ Follow Nurse, Brazilian National Cancer Institute. \\ ${ }^{6}$ Nurse PHD - Postgraduate Program in Nursing and Biosciences, Universidade Federal do Estado do Rio de \\ Janeiro - UNIRIO. \\ ${ }^{7}$ Nurse PHD - Postgraduate Program in Nursing, Universidade Federal do Rio de Janeiro - UFRJ.
}

\begin{abstract}
:
Objectives: To describe the nursing care plan from the North American Nursing Diagnosis Association (NANDA) diagnoses, prescribed to gastric adenocarcinoma patients in the first nursing consultation carried out at the ambulatory of the Brazilian National Cancer Institute and to characterize the sociodemographic and clinical profile of these patients.

Methods: Observational, descriptive and prospective study based on medical records during the first nursing consultation to gastric adenocarcinoma patients assisted at the Multidisciplinary Ambulatory Group for Research and Treatment of Gastric Cancer. For descriptive statistical analysis, we used the Microsoft Office Excel@, version 2016. The study was approved by institutional review board of the Brazilian National Cancer Institute. Informed consent was obtained from all participants.

Results: Fifty patients were included in the study, predominantly men, with mean age of 62,42 years $(S D=$ $\pm 12,02)$, married, with low schooling and low income, smokers, eventual users of alcohol $(n=37)$, in advanced tumor stage $(n=90)$ and with initial symptoms characteristics of this phase. Twelve nursing diagnoses were common to all patients and the most frequently prescribed care were related to the feeding problems control, pain and lack of institutional routines knowledge.

Conclusion: The taxonomy used allowed the nurse to identify problems and prescribe care according to its professional competence, using a standard language pattern to register in the medical records, allowing clear communication among the members of health team, based on the signals and symptoms presented by the patients. In this taxonomy, nursing diagnosis related to episodes of active bleeding was not found.
\end{abstract}

Keywords: Oncology nursing-Nursing diagnosis-Outpatient healthcare-Adenocarcinoma-Gastric neoplasms

\section{Introduction}

Gastric cancer is considered a national and worldwide health problem [1] mainly in developing countries, is the fifth most common neoplasia and the third in mortality in the world, affecting men approximately twice as often as women [2]. In Brazil is the fourth highest type of cancer, where there are an estimated 12,920 new cases in men and 7,600 in women for 2016/2017 [3].

Several risk factors can make a person more likely to get stomach cancer, as diet that have large amounts of salted or cured foods, infection with Helicobacter pylori, peptic ulcer disease, familial history of diffuse gastric cancer, gastric surgery, among others [4]. Of the various histological types, the most common is adenocarcinoma, corresponding to $95 \%$ of all gastric tumors, being lymphoma and leiomyosarcoma the least frequent histologic types. The symptoms of gastric cancer are often nonspecific, which makes the early diagnosis more difficult in many cases. The prognosis will depend on the staging at diagnosis, but it can also be influenced by age, histological type and socio-economic level. Treatment is multimodal, involving chemotherapy, surgery and radiotherapy, but the complete surgical resection offers a better prognosis where possible $[5,6,7]$.

The social support to the patient and its family caregiver during treatment and rehabilitation requires intervention/approach of different members of the health team and should be intensive to proceed to the curative treatment or even palliative in order to provide better quality of life. For this reason, at Brazilian National Cancer Institute a multidisciplinary group was created to systematize assistance to patients with gastric cancer, the multidisciplinary Group for Research and Treatment of Gastric Cancer. The team, composed by surgeons, nurse, social worker, nutritionist, psychologist and physiotherapist, in addition to evaluating all the needs of the 
clients, also optimizes referrals for laboratory and imaging examination. The role of the nurse in the group is essential, because it establishes a link among different professional categories, which has favored the systematic approach, by facilitating the systematization of nursing care at the ambulatory.

In the Brazilian health institutions, the nurse's practice in a systematic and autonomous way is regulated by Law n. 7,498 of June 25, 1986 and endorsed by Resolution of the Nursing Federal Council, n. 358 of October 15, 2009, which provide for the systematization of nursing care. In this context, the nurse's performance in the care of the patient with gastric cancer aims to identify the needs and provide well-being, using the ability to see, hear, observe, feel, care, teach, be available to make the necessary, comforting, sharing knowledge and educating for the self-care or teaching the family caregiver how to take care of it at home [8].

This enables the nurse to take care with scientific and humanized support, and the construction of a know-how for differentiated and organized nursing care, provided to the oncological patient with the aim of preserving its individuality, customs and way of life and from that, meeting its needs and improve its quality of life. Such an initiative should be disseminated through the oncological nursing community to be enhanced and receive contributions.

Some of the steps in the systematization are the diagnosis through a taxonomy and the nursing care plan. Hence, the objectives of this study were to describe the nursing care, from the North American Nursing Diagnosis Association (NANDA) [9] diagnoses addressed to patients with gastric adenocarcinoma in the first nursing consultation conducted at the Brazilian National Cancer Institute and characterize the sociodemographic and clinical profile of the patients with gastric adenocarcinoma.

\section{Methods}

We conducted an observational, descriptive and prospective study. The research involved the records of the first nursing consultation for 50 patients with gastric adenocarcinoma attended at the Multidisciplinary Ambulatory Group for the Gastric Cancer Studies and Treatment, in the Abdominal-pelvic Surgery Division. Data were collected between June and October 2016. The study variables were sex, age, color (according to the Brazilian Institute of Geography and Statistics classification), education, marital status, professional status, household income, place of birth, county, Performance Status based on Eastern Cooperative Oncology Group ECOG applied at patient admission, tumor staging, smoking, drinking, early symptoms of the disease, time of onset symptoms, nursing diagnosis according to NANDA Taxonomy and nursing care actions prescribed.

Data were performed using descriptive statistic techniques (absolute frequency, percentage, standard deviation, median) by using the "Statistical Package" of the Microsoft Office Excel®, 2016 version. The study project was evaluated and approved by the institutional review board of the Brazilian National Cancer Institute. All the patients authorized their participation through the informed consent.

\section{Results}

During the data collection period, from June 01 to October 31, 2016, 107 patients with gastric adenocarcinoma were admitted in the Abdominal-pelvic Surgery Division. Of these 107 patients, 26 were under emergency conditions due to gastrintestinal bleeding or obstructive syndromes, requiring hospitalization on the day of admission to the institution. Thus, 81 of them were scheduled for the Multidisciplinary Ambulatory of the Group for Research and Treatment of Gastric Cancer, what happens weekly on Fridays. Of 81 scheduled patients, 19 missed the consultation, alleging that they faced difficulty with transport or impossibility of being accompanied by the family or other caregiver. Of 62 remaining patients, 07 needed urgency assistance by the Endoscopy Service due to the need of nasoenteric intubation and 05 required hemotransfusion.

Thus, 50 patients were attended in the first-time consultation by the nurse and agreed to participate in the research. The mean age for the sample was 62.42 years $(\mathrm{DP}= \pm 12.02)$, most were men $(\mathrm{n}=29)$, married $(\mathrm{n}$ =34), with low education level and low income, maintaining professional activity (table 1). Most participants stated to have been born in Rio de Janeiro state $(n=28 ; 56 \%)$ and one of them was stranger. With respect to the county, most reported living in Rio de Janeiro city $(\mathrm{n}=32 ; 64 \%)$ and the remaining lived in the neighborhood cities.

Table 1. Sociodemographic characteristics of cases with gastric adenocarcinoma attended in the first-time nursing consultation - NCI, Rio de Janeiro, Brazil.

\begin{tabular}{|l|l|l|}
\hline Variable & N & \% \\
\hline Age $*$ & & \\
\hline $35-50$ & 10 & 20 \\
\hline $51-60$ & 40 & 80 \\
\hline Gender & & \\
\hline Female & 21 & 42 \\
\hline Male & 29 & 58 \\
\hline Colour & & \\
\end{tabular}




\begin{tabular}{|l|l|l|}
\hline White & 16 & 32 \\
\hline Light Brown & 25 & 50 \\
\hline Black & 9 & 18 \\
\hline Marital status & & \\
\hline Single & 6 & 12 \\
\hline Married/Consensual union & 34 & 68 \\
\hline Divorced/Separated & 6 & 12 \\
\hline Widowers & 4 & 8 \\
\hline Education level & & \\
\hline None & 31 & 62 \\
\hline Elementary & 12 & 24 \\
\hline High school & 6 & 12 \\
\hline Higher education & 1 & 2 \\
\hline Professional situation & & \\
\hline Active Employed & 26 & 52 \\
\hline Retired & 20 & 40 \\
\hline Not work & 4 & 8 \\
\hline Monthly Income ** & & \\
\hline R 650.00 a R 1.500 .00 & 32 & 64 \\
\hline $\mathrm{R} \$ 1.501 .00$ a R $\$ 2.500 .00$ & 14 & 28 \\
\hline R 2.501 .00 a $\$ 3.500 .00$ & 4 & 8 \\
\hline Total & $\mathbf{5 0}$ & $\mathbf{1 0 0}$ \\
\hline
\end{tabular}

$*$ Mean age $=62.42 ; \mathrm{DP}= \pm 12.02$.

$* *$ Mean monthly income $=\mathrm{R} \$ 1092.96 ; \mathrm{DP}= \pm 1069.14$

With respect to their life-style behaviors, patients reported smoking $(n=30 ; 60 \%)$ and alcoholic drinking intake $(\mathrm{n}=37 ; 52.6 \%)$. The other clinical characteristics are shown in table 2. Advanced stage disease was observed in $90 \%$ of patients.

Table 2. Clinical characteristics of cases of gastric adenocarcinoma attended in the first-time nursing consultation - NCI, Rio de Janeiro, Brazil.

\begin{tabular}{|l|l|l|}
\hline Variable & N & \% \\
\hline Performance Status (ECOG) & & \\
\hline 0 & 17 & 34 \\
\hline 1 & 29 & 58 \\
\hline 2 & 3 & 6 \\
\hline 3 & 1 & 2 \\
\hline 4 & 0 & 0 \\
\hline Tumor Staging & & \\
\hline I & 2 & 4 \\
\hline II & 3 & 6 \\
\hline III & 20 & 40 \\
\hline IV & 25 & 50 \\
\hline Time of onset symptoms & & \\
\hline$<3$ months & 7 & 14 \\
\hline $3-6$ months & 28 & 56 \\
\hline $7-9$ months & 7 & 14 \\
\hline 10 - 12 months & 4 & 8 \\
\hline$>12$ months & 4 & 8 \\
\hline Total & $\mathbf{5 0}$ & $\mathbf{1 0 0}$ \\
\hline
\end{tabular}

According to the patients, the initial symptoms of the disease were very varied. They show characteristics of advanced disease. The most frequent complaints are listed in table 3.

Table 3. Initial complaints reported by patients with gastric adenocarcinoma evaluated at the first nursing consultation - NCI, Rio de Janeiro, Brazil.

\begin{tabular}{|l|l|l|}
\hline Symptomsreported & N & \% \\
\hline Weightloss & 45 & 90 \\
\hline Vomiting & 43 & 86 \\
\hline Intestinal constipation & 43 & 86 \\
\hline Nausea & 42 & 84 \\
\hline Anemia & 42 & 84 \\
\hline Epigastric pain & 41 & 82 \\
\hline Bleeding & 40 & 80 \\
\hline Reflux sensation & 40 & 80 \\
\hline
\end{tabular}




\begin{tabular}{|l|l|l|} 
Post prandial plenitude & 38 & 76 \\
\hline Abdominal distension & 34 & 68 \\
\hline Retrosternal pyrosis & 33 & 66 \\
\hline Asthenia & 32 & 64 \\
\hline Hyporexia & 24 & 48 \\
\hline Dysphagia & 19 & 38 \\
\hline
\end{tabular}

A total of 22 nursing diagnoses were detected according to the NANDA taxonomy in the sample studied. Here are described those that were present in all patients, identified through physical examination and interview at the first nursing consultation and the prescribed care for the patients.

Table 4. Nursing diagnoses identified and care prescriptions for patients with gastric adenocarcinoma seen at the first nursing consultation - NCI, Rio de Janeiro, Brazil.

\begin{tabular}{|c|c|c|}
\hline NursingDiagnosis. & $\begin{array}{l}\text { Defining characteristics } \\
\text { found in the sample }\end{array}$ & NursingPrescription. \\
\hline $\begin{array}{l}\text { 1. Unbalanced nutrition: less than } \\
\text { the body needs, related to gastric } \\
\text { injury. }\end{array}$ & $\begin{array}{l}\text { Food ingestion less than the } \\
\text { recommended daily portion } \\
\text { due to inappetence and early } \\
\text { gastric fullness; weight loss } \\
\text { even with adequate ingestion } \\
\text { of food due to extensive } \\
\text { gastric injury. }\end{array}$ & $\begin{array}{l}\text { 1. To referral for evaluation with doctor and nutritionist } \\
\text { regarding the need for a nasoenteral catheter. } \\
\text { 2. To forward to the nutritionist. } \\
\text { 3. To orient and teach nasoenteral tube feeding (NTF) to } \\
\text { prevent obstruction by medicines and food. } \\
\text { 4. To orient regarding the fixation of the NTF to avoid } \\
\text { displacement. } \\
\text { 5. To measure the weight and record the gain or loss } \\
\text { variations. } \\
\text { 6. To alert the doctor and nutritionist about weight loss or } \\
\text { complaints of nausea, vomiting, diarrhea or constipation. }\end{array}$ \\
\hline $\begin{array}{l}\text { 2. Nausea related to gastric injury, } \\
\text { rapid infusion of the enteral diet, or } \\
\text { food retention in the stomach for } \\
\text { long periods. }\end{array}$ & $\begin{array}{l}\text { Aversion to food; Bitter taste } \\
\text { in the mouth; Sialorrhea; } \\
\text { And craving for vomiting or } \\
\text { feeling faint. }\end{array}$ & $\begin{array}{l}\text { 1. To orient to avoid ingesting large amounts of liquids } \\
\text { during meals in order to avoid rapid dilation of the } \\
\text { stomach when feeding is orally. } \\
\text { 2. To orient for slow administration of the diet and } \\
\text { fractionated in small volumes when NTF is present. } \\
\text { 3. To orient for the use of the prescribed antiemetic } \\
\text { medicine. } \\
\text { 4. To orient oral hygiene to improve the taste. } \\
\text { 5. To observe abdominal distension and complaint of pain } \\
\text { and refer to the physician to evaluate gastric obstruction. }\end{array}$ \\
\hline $\begin{array}{l}\text { 3. Poor fluid volume or risk of poor } \\
\text { fluid volume related to detour that } \\
\text { affect the ingestion of liquids such } \\
\text { as gastric obstruction or nausea / } \\
\text { vomiting. }\end{array}$ & $\begin{array}{l}\text { Alteration of skin turgor; } \\
\text { decreased urine output; dry } \\
\text { mucosa and skin; elevated } \\
\text { hematocrit. }\end{array}$ & $\begin{array}{l}\text { 1. To orient the importance of oral water intake or by NTF } \\
\text { and suggest small fractional volumes throughout the day. }\end{array}$ \\
\hline $\begin{array}{l}\text { 4. Constipation and / or risk of } \\
\text { constipation related to low water } \\
\text { and fiber intake. }\end{array}$ & $\begin{array}{l}\text { Anorexia; abdominal } \\
\text { distension; effort to evacuate; } \\
\text { hard and dry stools; } \\
\text { complaint of indigestion; } \\
\text { reduced frequency and stool } \\
\text { volume. }\end{array}$ & $\begin{array}{l}\text { 1. To forward for evaluation with nutritionist for dietary } \\
\text { planning appropriate to the patient. } \\
\text { 2. To stimulate water intake and small walks (when } \\
\text { possible). } \\
\text { 3. To orient for use of laxative, when prescribed. } \\
\text { 4. To verify the compliance and acceptance of the diet } \\
\text { prescribed by the nutritionist. } \\
\text { 5. To advise the attendance to the Emergency Unit in cases } \\
\text { of long periods of constipation (over } 10 \text { days). }\end{array}$ \\
\hline $\begin{array}{l}\text { 5. Impaired skin integrity related to } \\
\text { low fluid intake and poor nutrition. }\end{array}$ & $\begin{array}{l}\text { Alteration of skin hydration, } \\
\text { manifested by decreased } \\
\text { turgor, dry skin and } \\
\text { desquamation. }\end{array}$ & $\begin{array}{l}\text { 1. To stimulate water intake by oral or nasoenteral tube. } \\
\text { 2. To stimulate the use of moisturizing lotion. }\end{array}$ \\
\hline $\begin{array}{l}\text { 6. Body image disorder related to } \\
\text { changes in body structure (weight } \\
\text { loss), fear of the reaction of others } \\
\text { and focus on previous appearance. }\end{array}$ & 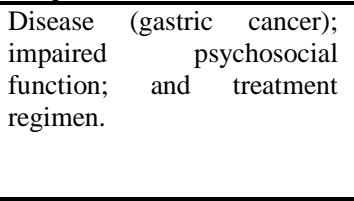 & $\begin{array}{l}\text { 1. To explain the reasons for weight loss and pale skin and } \\
\text { how it can be reversed. } \\
\text { 2. To forward to support of Psychology. } \\
\text { 3. Toverify the compliance and acceptance of the } \\
\text { prescribed diet and check with the nutritionist if } \\
\text { adjustments are needed. }\end{array}$ \\
\hline $\begin{array}{l}\text { 7. Risk of bleeding related to } \\
\text { advanced gastric lesion. }\end{array}$ & Gastrointestinal disorders. & $\begin{array}{l}\text { 1. To orient on signs of bleeding (melena and } \\
\text { hematemesis) and when and how to look for the } \\
\text { institution's Emergency Unit. } \\
\text { 2. To monitor hemoglobina level. }\end{array}$ \\
\hline $\begin{array}{l}\text { 8. Fatigue related to physiological } \\
\text { condition, malnutrition, negative } \\
\text { life event and sleep deprivation }\end{array}$ & $\begin{array}{l}\text { Tiredness; drowsiness; } \\
\text { apathy; insufficient energy } \\
\text { and impaired competence to } \\
\text { maintain the usual level of } \\
\text { physical activity. }\end{array}$ & $\begin{array}{l}\text { 1. To orient for more frequently rest throughout the day. } \\
\text { 2. To recommend to avoid excessive physical effort, to not } \\
\text { waste energy. } \\
\text { 3. To monitor blood count to assess the presence of major } \\
\text { anemia. } \\
\text { 4. To refer for medical evaluation if necessary. }\end{array}$ \\
\hline 9. Pain related to gastric injury. & Change in sleep pattern, self- & 1. To evaluate and record the level of pain according to the \\
\hline
\end{tabular}




\begin{tabular}{|c|c|c|}
\hline & $\begin{array}{l}\text { report of pain intensity using } \\
\text { Visual Analogue Scale } \\
\text { (VAS) and pain report by } \\
\text { family member. }\end{array}$ & $\begin{array}{l}\text { Visual Analog Scale. } \\
\text { 2. To refer to medical evaluation for analgesia. } \\
\text { 3. To orient the correct use of the prescribed analgesic. } \\
\text { 4. To advise on avoiding long periods of fasting that may } \\
\text { favor the onset of pain due to the presence of hydrochloric } \\
\text { acid. }\end{array}$ \\
\hline $\begin{array}{l}\text { 10. Fear related to disease and } \\
\text { treatment. }\end{array}$ & $\begin{array}{l}\text { Stimulus understood as threat } \\
\text { (gastric cancer) and } \\
\text { increased tension reported. }\end{array}$ & $\begin{array}{l}\text { 1. To adopt an empathic posture with the patient, leaving } \\
\text { him or her free to express their doubts or complaints. } \\
\text { 2. To provide emotional support by talking to the patient } \\
\text { about the illness (not always terminal) and clarifying about } \\
\text { the treatment. } \\
\text { 3. Forward to support of Psychology. } \\
\text { 4. To encourage the patient to return according to their } \\
\text { need. } \\
\text { 5. To provide information so that the patient and his / her } \\
\text { family member know the steps of the treatment and feel } \\
\text { instrumented to face their care routine. }\end{array}$ \\
\hline $\begin{array}{l}\text { 12. Deficient knowledge related to } \\
\text { institutional resources for the } \\
\text { treatment of the disease and } \\
\text { location of services in the physical } \\
\text { space of the hospital. }\end{array}$ & 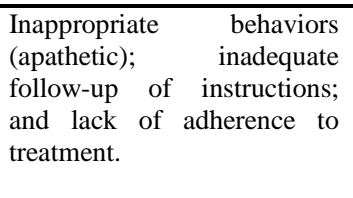 & $\begin{array}{l}\text { 1. To inform about the exams, treatments and rights of the } \\
\text { patient and family. } \\
\text { 2. To provide the booklets about the institutional resources, } \\
\text { so that the patient has another source for the clarification } \\
\text { of doubts. } \\
\text { 3. To inform on available services and their location. }\end{array}$ \\
\hline
\end{tabular}

\section{Discussion}

The sociodemographic characteristics described in Table 1 are in accordance with the literature. Although most patients lived in the city of Rio de Janeiro $(n=32 ; 64 \%)$, the rest were distributed in cities farther from the capital and reported problems with transportation, which made it difficult to access consultations and examinations, delaying the diagnosis of the disease, and may impair adherence to treatment due to lack of resources for transportation and food costs on the days of consultations and examinations. It leads us to reflect on the reference to the universal right to health and what type of access was made available to the population, in other words, which model of health care would contribute to guarantee the necessary support to meet the social health needs of the user [10,11].

Socioeconomic factors such as income, education, location and living conditions interfere in the access to health services, favoring or not the demand and use of them. Significant social inequalities among population groups lead to difficulties in accessing health services and delays in the diagnosis of various diseases, especially chronic insidious and long-term diseases such as gastric cancer $[12,13]$. This may have been one of the reasons for the diagnosis of advanced stage III and IV of gastric cancer, as perceived in $90 \%$ of the sample studied (Table 2).

The advanced stage of the disease also affected the Performance Status Scale (ECOG), which showed a score of 1 in more than half of the patients evaluated $(n=29 ; 58 \%)$. Scoring 1 is equivalent to $70-80 \%$ on the Karnofsky Scale, where intense physical activity is restricted and although the patient can take care of himself, he is not able to work or perform light activities with much effort, aspect negative for the economic status of patients [14].

The time to onset of symptoms reported by most participants was between 3 and 6 months (Table 2). Many reported heartburn and gastric discomfort, being then performed self-medication or symptomatic treatment in primary health care, without investigation of the origin of the pain. The disease was only investigated with endoscopic examination when there were emergency situations such as persistent vomiting, gastric bleeding and intense pain. These findings are in line with what has been described in other studies, which explain that the symptoms of gastric cancer are usually nonspecific and manifested when the disease is in advanced stage or there are metastases. The main complaints such as abdominal pain, postprandial fullness and weight loss are like those of peptic ulcer [14,15].

In this study, the patients' complaints were the same (Table 3), plus abdominal distension, vomiting, nausea and bleeding, showing obstructive conditions and involvement of the muscular and serous layers of the stomach, characteristics of extensive and infiltrating tumor. The bleeding, reported by respondents, was probably caused by erosive lesions of the gastric mucosa and spasms of the musculature, accompanied by nausea and vomiting. The literature cites that occur in about 10 to $15 \%$ of cases of stomach cancer $[5,14]$. 
However, in the studied sample, $80 \%$ of the patients reported frequent episodes of bleeding, evidenced by episodes of hematemesis and melena, sufficient for negative and important changes in hemoglobin and hematocrit levels.

Although does not appear in the nursing diagnosis "bleeding" in the NANDA taxonomy, it was found in $80 \%$ of the studied sample, manifested by melena, hematemesis and hemoglobin below $7 \mathrm{~g} / \mathrm{dL}$. The nurse referral to the medical evaluation of the patients with this problem and blood transfusion was fundamental for the resolution of this intercurrence and improvement of their health status, allowing stabilization of the clinical picture, as already studied [16].

The advanced stage of the disease was also manifested in the identified nursing diagnoses. Diagnoses such as body image disorder, risk for affected skin integrity, fatigue and constipation were a consequence of unbalanced nutrition for less than bodily needs, nausea and poor fluid volume. Malnutrition in cancer can lead to a condition known as cachexia, which has varied clinical manifestations such as anorexia, severe weight loss, depletion of adipose and muscular tissue, atrophy of visceral organs, anemia, among others. Patients with can cermay present malnutrition already at the time of diagnosis of the disease and it is associated with increased morbidity and mortality $[17,18]$.

In clinical practice, even if the patient does not report difficulty swallowing food, we should evaluate the indication of the nasoenteral tube when the rapid and progressive loss of weight is observed, since the disease affects the process of absorption of food in the stomach. It is necessary to take the patient to realize the benefits of the probe diet, when it is indicated, as it can provide relief from vomiting by reducing the volume of food retained in the stomach. Also, it is important that the patient's nutritional status is restored to allow the patient to receive cancer treatment, either surgery or chemotherapy. In the professional experience, we observed that the younger patients presented greater resistance to the acceptance of the use of nasoenteral tube feeding, we attribute this mainly to the non-acceptance of the alteration of the corporal image caused by this device.

It has been observed that the medical diagnosis of advanced gastric cancer leads the patient to respond differently from the one who receives the diagnosis of other diseases. There is the idea that cancer is associated with pain, invasive and disabling treatments and death. For these reasons, cancer is the most frightening disease in people [19]. This aspect justifies nursing diagnoses of fear, insomnia and pain. Patients reported more difficult times at night, with more pain and concerns about their future. Even so, they find it difficult to complain to doctors about their sleeping problems, often making the consequences of insomnia underestimated in the face of the cancer itself. Insomnia may also be a secondary symptom to depression or anxiety [20].

Studies show that pain, when not alleviated, limits the individual in daily living activities, changes appetite, sleep patterns, ambulation, mobilization, mood, leisure, professional, social and family activities. It can trigger frustration, depressive process, social and family isolation, exacerbation of fear and pain. Pain, when not properly treated, affects the quality of life of patients and their caregivers in all dimensions, physical, psychological, social and spiritual [21,22].

Pain is defined by the International Association for the Study of Pain as an unpleasant sensory and emotional experience associated with actual or potential tissue damage; pain is experienced by 50 to $70 \%$ of individuals with cancer in the early stage of the disease. And in the more advanced stages, this percentage can reach $90 \%$. In this sense, whenever nurses hear the pain complaint, they should direct actions for their control, in addition to intervention and monitoring of the results to levels considered acceptable by the patient $[22,23]$.

The diagnosis of nursing "deficient knowledge" was related to the lack of knowledge about cancer treatment, the modalities available and how the disease will be managed by the health team. Added to this was the fear of the prospect of response to treatment and insecurity about institutional resources, given that it is a public institution. As defining characteristics, we find inappropriate behaviors (apathetic), inadequate follow-up of instructions and lack of adherence to treatment [9].

Communication is one of the tools that the nurse uses to supply the patient's knowledge deficiency [24]. Thus, guidelines were prescribed for most of the nursing diagnoses identified (Table 1), using this tool in meeting with the patient, explaining the problems and care in colloquial language so that they understood it, using drawings and booklets to promote the assimilation of what was explained. Communication was the instrument mediating the humanization of care during the nurses' work process, to establish an effective relationship through dialogue, sensitive listening and conversation, capable of transforming the client's insecurity and fear position.

In this context, the presence of the family was essential for the nurse, since the patient's spokespersons represent the feelings, attitudes, and sociocultural behaviors internalized in the patient's life. They become the mediators of the patient in the hospital and bring some comfort to the patient and even to the health team, through their interaction with the team.

According to Melo and cols. [25], as it happens to the diagnosed patient, his family also suffers from doubts and insecurities arising from this news. Values, previous knowledge, family history, and treatment expectations may interfere with how to deal with illness and care for the sick family member. It is rare that they do not present psychological disorders such as depression and anxiety throughout the course of treatment. Each

DOI: 10.9790/1959-0601048693 $\quad$ www.iosrjournals.org $\quad 91 \mid$ Page


procedure to be performed brings to the patient and his family the anguish, the fear and the uncertainty if everything is happening within the care routine or if it means evolution of the disease [26]. Knowing the reactions and feelings of family members and the strategies used to deal with this situation can contribute to the development of care prescriptions that reduce the suffering of both.

We seek to involve the caregiver as much as possible, providing advice about the neoplasia, the most common signs and symptoms, the conditions to seek emergency care (severe pain, infections, bleeding and constipation) and make the institution phone available to avoid doubts and avoid unnecessary detachments. The goal is to provide the patient and caregiver with the best care possible, reducing the effects of illness and treatment. In addition, emotional support is provided to the caregiver, who also suffers consequences for dedication to patient care, especially changes in lifestyle, work and leisure habits.

\section{Final Considerations}

The out patient nursing consultation was the mediating instrument of the humanization of care during the nurses' work process, in order to establish an effective relationship through dialogue, sensitive listening and conversation, capable of transforming the position of insecurity and fear of the patient in a more collaborative attitude and adherence to the treatment and care offered. We thought it favored the interaction of the patient with the health team, although other studies should bed eveloped to evaluate the effects of the nursing consultation on the clinical response orquality of life of the patients.

Nursing diagnosis, according to NANDA, based care prescription to the needs affected he for the outpatient in the first week after admission to treatment at the institution. It opened new possibilities for care, because it allowed nurses to apply scientific knowledge to identify problems and prescribe care according to their professional competence, using a standard language for recording in the medical record, enabling clear communication among health team members, based on signs and symptoms presented by the patients.

In the taxonomy employed, no nursing diagnosis was found related to episodes of active bleeding attributed to most of the patients in this study. Also, the lack of some defining characteristics and related factors for some of the diagnoses used was identified, which implies the need to entangle efforts to develop other studies in the nurses' clinical practice with a view to complementing this taxonomy.

\section{References}

[1]. J. A. Ajani, J. S. Barthel, D. J. Bentrem et al, Esophageal and esophagogastric junction cancers, J Natl ComprCancNetw, 9(8), 2011, 830-887.

[2]. GLOBOCAN. International Agency for Research on Cancer (IARC) (2012). Stomach Cancer Estimated Incidence, Mortality and Prevalence Worldwide in 2012.

[3]. Brasil. Instituto Nacional de Câncer José Alencar Gomes Da Silva (INCA). Estimativa 2016: Incidência de Câncer no Brasil. Coordenação de Prevenção e Vigilância, (Rio de Janeiro: INCA, 2016).

[4]. E.C.R. Campos, E. B. A. Pinheiro, R. L. Baldissera et al, Análise de fatores prognósticos no tratamento cirúrgico do câncer gástrico, Rev Med Res, 4(2), 2012, 101-107.

[5]. Brasil. Ministério da Saúde. Instituto Nacional do Câncer. Câncer de estômago. (Rio de Janeiro: INCA; 2010).

[6]. M. T. S. Guedes, J. P. Jesus, O. Souza Filho, et al, Clinical and epidemiological profile of cases of deaths from stomach cancer in the National Cancer Institute, Brazil, Ecancer medicalscience [on line], 8(445), 2014, http://www.ncbi.nlm.nih.gov/pmc/articles/PMC4118726/

[7]. S.D. Ramsey, A. Bansal, C. R. Fedorenko, et al, Financial insolvency as a risk factor for early mortality among patients with cancer, J ClinOncol, 34(9), 2016, 980-986.

[8]. A. L. B. L. Barros, J. L. Lopes, A legislação da assistência de enfermagem, Enfermagem em Foco, 1(2), $2010,63-65$.

[9]. T.H. Herdman, S. Kamitsuru (Orgs.), Diagnósticos de enfermagem da NANDA: Definições e classificação 2015-2017, 10 (Porto Alegre: Editora ARTMED, 2015).

[10]. American Cancer Society, Global Cancer Facts \& Figures, 3 (Atlanta: American Cancer Society, 2015).

[11]. R.C.T. Mioto, V.M.R. Nogueira, Política social e Serviço Social: os desafios da intervenção profissional, R Katál, 16(sp.n), 2013, 61-71.

[12]. M.S.P.L. Souza, R. Aquino, S. M. Pereira, et al, Factors associated with geographic access to health services by TB patients in three State capitals in Northeast Brazil, Cad. Saúde Pública, 31(1), 2015, 111-120.

[13]. S.D. Ramsey, A. Bansal, C. R. Fedorenko, et al. Financial insolvency as a risk factor for early mortality among patients with cancer. J ClinOncol,34(9), 2016, 980-986.

[14]. ECOG-ACRIN Cancer Research Group. Comparing the ECOG Performance Status to the Karnofsky Performance Status. <http://ecog-acrin.org/resources/ecog-performance-status>

[15]. J.C.L. Campelo, L.C. Lima, Clinical and epidemiological profile of early gastric cancer in a referral hospital in Teresina, Piauí, RevistaBrasileira de Cancerologia, 58(1), 2012, 15-20.

[16]. H. A. E. Bayumi, Clinical outcomes and patient satisfaction assessment among upper gastrointestinal bleeding at Qena University Hospital at Upper Egypt, IOSR-JNHS, 5(6), 2016, 130-139.

[17]. R.C. Fortes, V. L. Recova, A. L. Melo, et al, Gastrointestinal alterations in patients with colorectal cancer on clinical trial supplemented with Agaricussylvaticus fungus, Rev Bras colo-proctol, 30(1), 2010, 45-54

[18]. T. Lotice, L. B. B. Antunes, A. R. F. Melhem, et al, Prevalência de perda de peso, caquexia e desnutrição em pacientes oncológicos, Revista Uniabeu, 7(17), 2014, 107-124.

[19]. S. Mukherjee, O imperador de todos os males - uma biografia do câncer (São Paulo: Ed. Companhia das Letras, 2012).

[20]. R. Rafihi-Ferreira, M. R. Z. Soares, Insomnia in patients with breast cancer, EstudPsicol (Campinas), 29(4), $2012,597-607$.

[21]. O. A. Zargar, K. Amin, Improving quality of life in cancer patients, IOSR - JNHS, 5(1), 2016, 17-23. 
[22]. M. Stübe, C. T. Cruz, E. R. R. Benetti, et al, Perceptions of nurses and pain management of cancer patients. REME - Rev Min Enferm, 19(3), 2015, 704-710.

[23]. M.Z. Santos, D.M. Kusahara, M.L.G. Pedreira, The experiences of intensive care nurses in the assessment and intervention of pain relief in children, Rev Esc Enferm USP, 46(5), 2012, 1074-81.

[24]. F.S. Pott, T. Stahlhoefer, J. V. C. Felix, M. J. Meier, Comfort and communication measures in nursing caring actions for critically ill patients, Rev Bras Enferm, 66(2), 2013, 174-179.

[25]. M. C. B. Melo, E. N. Barros, M. C. V. A. Campello, et al, Family functioning of patients with cancer, PsicologiaemRevista, 18(1), 2012, 73-89

[26]. G.V. Farinhas, M.I. Wendling, L. L. Dellazzana-Zanon, Psychological impact of a cancer diagnosis on the family: a case study on the perception of the caregiver, PensandoFamílias, 17(2), 2013, 111-129. 